\title{
THE ROLE OF FUSION OR WIRING IN THE TREATMENT OF ACUTE TRAUMATIC INSTABILITY OF THE SPINE
}

\author{
By Donald Munro, M.D., F.A.C.S. \\ Milton, Massachusetts, U.S.A.
}

IT was clearly shown in I96I (Munro) that the treatment of cervical cord and spinal injuries by internal, metallic fixation and bony fusion carries a greater mortality and causes more undesirable symptoms in the usual case than non-fusion therapy does.

The results of anatomical studies (Munro, 1965) also showed, in particular, that normal stability of the bones depended entirely on the spinal ligaments augmented by support from the para-spinal muscles.

This paper is in direct succession to the preceding one but has been expanded to include all levels of the vertebral column, the spinal cord and the cauda equina.

Material. Effective therapy cannot be devised for fractures and dislocations until after a detailed study of their characteristics has been made. I have reviewed, therefore, 583 of my records for this purpose. All the patients had been originally admitted to my care with a preliminary diagnosis of a cord or caudal injury. However, I 53 proved on further investigation to be useless for the present purposes.

These have been grouped in Table I, the reasons for their lack of inclusion being self-evident. Spondylosis, for example, has been covered previously (Brain, 1954; Munro, 1960). Gunshot wounds and stab wounds are too complicated for this analysis, and the I4 cases with an acute injury to the vascular supply of the cord are not suitable for a study of fractures except as the vertebrae themselves are affected.

TABLE I

Unanalysed Cases

\begin{tabular}{|c|c|c|c|c|c|}
\hline Classification & Cervical & Thoracic & Lumbo-sacral & Caudal & Totals \\
\hline $\begin{array}{l}\text { Spondylosis } \\
\text { Stab wounds } \\
\text { Gunshot wounds } \\
\text { Spinal anaesthesia } \\
\text { Vascular injury } \\
\text { Post-traumatic state } \\
\text { Congenital deformity } \\
\text { Cord disease }\end{array}$ & $\begin{array}{c}36 \\
2 \\
4 \\
1 \\
3 \\
3 \\
(\mathrm{I}) \\
3\end{array}$ & $\begin{array}{r}4 \\
2 \\
\text { I } 6 \\
\text { I } \\
7 \\
0 \\
\text { I } \\
0\end{array}$ & $\begin{array}{l}0 \\
0 \\
8 \\
3 \\
3 \\
0 \\
4 \\
\mathrm{I}\end{array}$ & $\begin{array}{l}0 \\
2 \\
3 \\
4 \\
1 \\
0 \\
2 \\
0\end{array}$ & $\begin{array}{r}40 \\
6 \\
31 \\
9 \\
14 \\
3 \\
7 \\
4\end{array}$ \\
\hline Totals & 52 & $3 \mathrm{I}$ & I9 & I2 & II 4 \\
\hline No data & 28 & 10 & $\mathbf{I}$ & 0 & 39 \\
\hline $\begin{array}{l}\text { Grand Totals } \\
\text { Omit }\end{array}$ & $\begin{array}{r}295 \\
7\end{array}$ & $\begin{array}{r}126 \\
5\end{array}$ & $\begin{array}{r}82 \\
3\end{array}$ & $\begin{array}{r}121 \\
26\end{array}$ & $\begin{array}{r}624 \\
4 \mathrm{I}\end{array}$ \\
\hline Corrected Totals & 288 & I2I & 79 & 95 & 583 \\
\hline
\end{tabular}

G

97 


\section{TABLE II}

Fractures, Subluxations, Dislocations, Discs, Scars

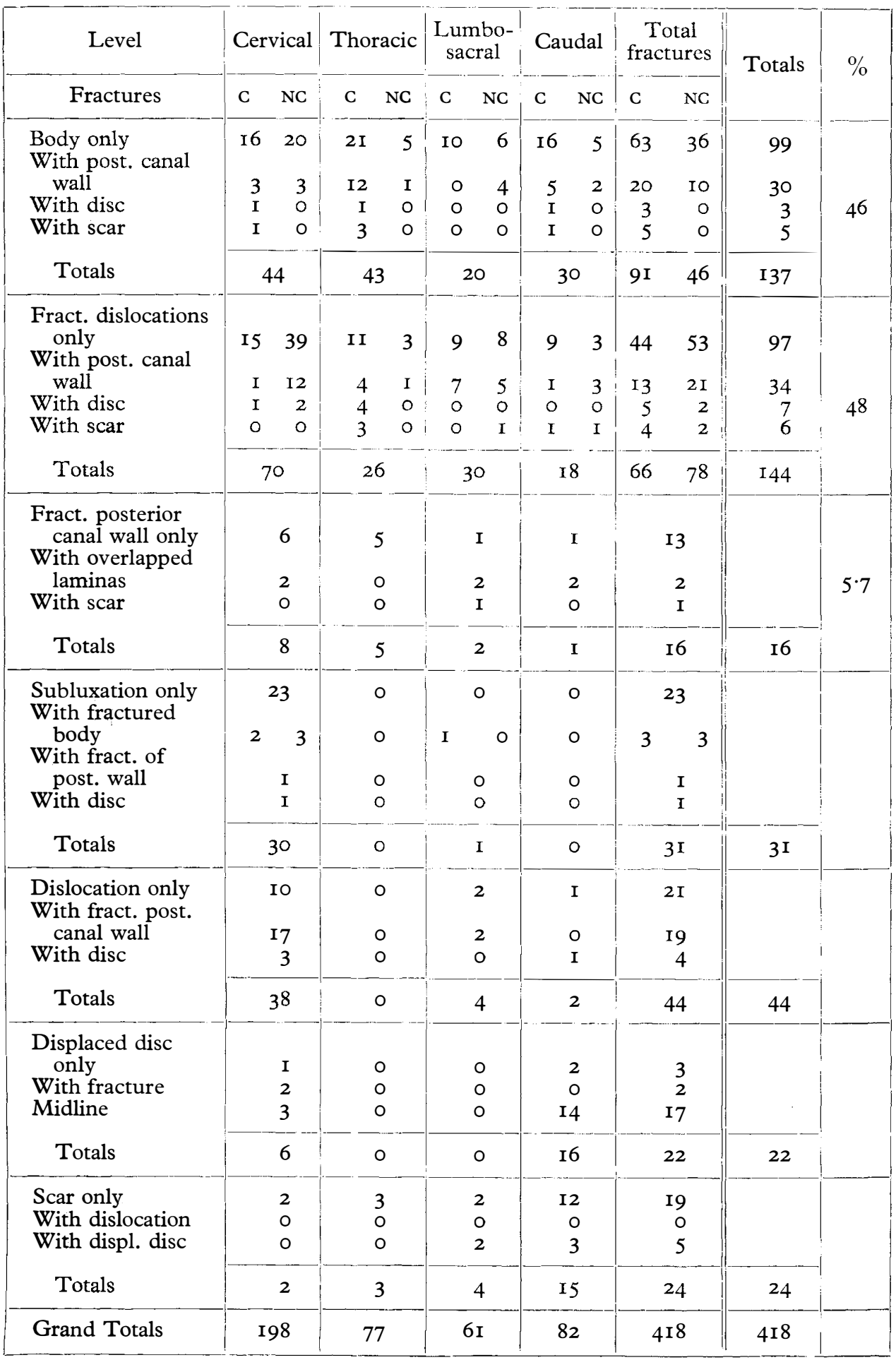

$\mathrm{C}=$ Compression. $\mathrm{NC}=$ Non-Compressed. 
The 39 cases in which essential data was missing included such examples as those with missing or incomplete X-ray examinations, and the 17 others that died Io days or less after the accident.

The distribution of the $4 \mathrm{I} 8$ cases that were suitable for analysis is shown in Table II.

Classification. The levels of bone injury have been determined by those of the major cord or caudal injury. In consequence, all cervical and those thoracic vertebral injuries above the tenth thoracic will correspond roughly to the eighth cervical and upper Io thoracic cord segments. The lumbar vertebrae from L2 through $\mathrm{S}_{5}$ inclusive will correspond to the cauda equina area.

However, because the distal part of the thoracic as well as all of the lumbar and sacral cord lie beneath the twelfth thoracic and first lumbar vertebrae bodies and the intervening disc (at times extending upward to include the II/I 2 disc or downward to include the body of the second lumbar vertebra), bone injuries here will have a very much wider effect in terms of functional damage to the cord, than would be expected from the small amount of bone involvement. These injuries have been classed therefore, as lumbo-sacral because of the parts of the cord that they have injured.

Attention is called to the predominance of subluxations, fracture-dislocations and dislocations-without-fracture in the cervical, the frequency of disc injuries in the cervical and caudal areas, and the virtual absence of subluxations and dislocations in all areas other than the cervical. The deforming scars included for study were all in old cases, caused severe deformities of the cord with considerable functional loss, and resulted either from the healing processes of old fractures or followed operations designed to correct bony deformities or to remove a chronically protruded disc.

Fractures. A fracture of the vertebral column was present in $7 \mathrm{I}$ per cent. It is probable that this approximates the usual rate of occurrence and is thus the main problem that the surgeon has to deal with in these injuries.

Compressed Fractures. A compression of a vertebral body was present in 53 per cent. Such a condition precludes the use of any fixation therapy except at the expense of leaving the bones permanently in an abnormal position. Leverage applied to the compressed body is ineffective and usually impossible.

Fractures without Associated Dislocation or Compression. Among such fractures are those of the postero-lateral wall of the spinal canal. This is an important group and is not usually recognised as a separate unit. They were present in 26 per cent. of all fractures and dislocations. In such fractures, the normal bony connections between the body and the fractured area in the same region is destroyed. Hence the latter cannot be used effectively to either move or immobilise the former.

Less common fractures of this type fell into four groups: vertical, chip, lineartransverse and those associated with an absorption of the injured body. Original films of this last condition have a ghost-like appearance, in which a nearly invisible centre lies surrounded by a thin bordering outline of visible bone. The former subsequently fills in and resumes a normal appearance. This occurred with fractures of the fifth and seventh cervical, the tenth thoracic and the first lumbar vertebrae. It was generally agreed that interference with the blood supply to the bone was the cause.

Obliteration of a thoracic interspace by impaction of adjoining bodies, and 
followed by a subsequent union, took place once. No disc was found at operation. Wedging or crush of the anterior edge of one body with the approximation of this to either body adjoining the wedge, and resultant angulation, is a form of compression fracture of a body. If a disc is extruded or destroyed as well, there is a posterior prominence at the level of the injury. Twenty-two patients had wedging - 7 cervical, 8 thoracic, 5 lumbo-sacral and 2 caudal.

Kyphosis. This describes a posterior angulation opposite a compressed fracture of a body. There were 20 among 297 fractures, an incidence of $7 \cdot 3$ per cent. It was present in one cervical and in 17, or I 6 per cent., of IO4 thoracic fractures. There were also two instances among the lumbo-sacral and none in the caudal series.

Hematorachis. This is a complication of fractures of the bodies and of operations on the lumbar spine. It is uncommon but insidious in its onset, and productive of considerable and permanent invalidism. It develops when the fracture or the surgical wound bleeds into the lumbar subarachnoid space through a tear in the meninges or as a post-operative haemorrhage. In the latter case it is not commonly recognised until it has become a post-operative scar. There were I3 instances of hematorachis in the 82 caudal injuries.

The fracture is always recognised and is treated at once by the application of a plaster cast. The possible complication, however, is either forgotten or neglected. It makes itself known shortly, nevertheless, at about the end of the second week of wearing the cast. The patient begins to complain at that time about an indefinite type of peripheral pain which is soon followed by peripheral motor paralysis. These symptoms are disregarded or else commonly ascribed to a 'too tight cast' which, accordingly, is replaced, but without having any effect on the symptoms. Finally, an exploratory laminectomy is done and the cauda is then found to be inextricably tangled and deformed by a mass of compressing adhesions. These are widespread, fibrous and may be of any amount or shape, including that of a 'string' which has encircled a variable part of the cauda and permanently destroyed its conductivity. These adherent bands have been formed by the organisation of the previously fluid blood, the presence of which has been unknown to the surgeon. If its presence had been considered as a possibility and had been then verified by an examination of the lumbar cerebrospinal fluid before the cast had been applied, the blood could have been easily drained while fluid and the aftermaths produced by its organisation prevented. Similarly this condition may also be duplicated after an otherwise successful removal of a protruded disc and cause, for the same reason, unexplainable and disabling neurological symptoms by compressing the root that lies in the operative field.

Fracture-Dislocations. There were I44 (34 per cent.) of these cases. Sixty-six, or 46 per cent., had compressed fractures of the bodies and, except for the added complication of the dislocation, presented no essential difference from the undislocated fractures of the bodies.

Knowledge of the direction of the dislocation will depend on the vertical visualisation of the spine above and below the injured area and is preferably shown by stereoscopic X-rays. A choice must then be made between an anterior movement of the injured and a posterior movement of the uninjured body, or vice versa, with a concomitant decision that the other of the two bodies has remained in place. Such difficulties are enhanced if the X-ray report consists of the terse statement that 'the films show a fracture-dislocation' without further amplification. This 
deficiency was present in $2 \mathrm{I}$ per cent. of the X-rays in my series. The greatest number (63 per cent.) were present in the lumbar and caudal groups.

Dislocations. These were counted with the fracture-dislocations, the unknown direction figures having been eliminated first.

Cervical. Ninety-nine of such injuries (69.7 per cent.) were dislocated anteriorly.' If the 30 subluxations, being in essence anterior dislocations, are added, the incidence of anterior dislocation in what is now 129 injuries rises to 76.5 per cent. Thus three out of four of the cervical dislocations were anterior.

Thoracic. Forty-eight per cent., or something less that one-half, were dislocated posteriorly, whereas 40 per cent. moved anteriorly. This difference of 8 per cent. cannot be considered significant. It does contrast, however, with the cervical figures in which the difference was about 40 per cent.

Lumbo-sacral. Sixty-six per cent. were dislocated posteriorly. This is approximately the same ratio between anterior and posterior directions as found in the cervical cases, but this time the predominant direction is posterior, the opposite of that in the cervical area.

Cauda. The cauda-equina figures, although too few to be entirely definitive, were anterior in 66 per cent., or approximately two-thirds of these cases.

It can be deduced from these figures, and indeed it is probable, that the factors which determine the usual site of fracture and the direction of dislocation depend in large part on the local shape of the injured arch, and that the amount of return toward normalcy after treatment of an injured spine is more truly measured by the post-therapy shape of the involved arch than by any other criterion.

The cervical arch is convex anteriorly with its apex at about the fifth vertebra ; the commonest fractures involve the fourth, fifth and sixth, and the commonest dislocation is anterior and centred in this same area. Only 3 I per cent. (38 out of I22 cases) had a compression fracture of their bodies. These figures would appear to indicate that, although the convex curve is effective against end-pressures, its shape favours displacement rather than destruction of the units that make it up. It depends for its strength on the postero-lateral wall of the spinal canal, the anterior and posterior common spinal ligaments and the discs. The vertebral bodies, of themselves, afford little aid except to act as anchors for the ligaments. The former move rather than fracture. Added strength for the arch as well as protection against post-injury motion of any fragments is afforded by the para-spinal musculature and its protective spasm. Such arrangements permit wide freedom of motion at the expense of diminished strength.

The thoracic arch is slightly convex posteriorly, shallow and flat below the sixth vertebra. Its shape assures strong resistance to end-pressures. No pure dislocations occurred in this area. Sixty-five per cent. of the fractured bodies were compressed. These figures can be taken to indicate that, rather than shift position, the vertebral bodies fracture, thus indicating great structural strength and a firm maintenance of position. The latter is attributable to the anterior spinal ligaments including the discs, the support of the massive para-spinal muscles and the proximity of the posterior chest wall. Such arrangements almost completely prevent motion in order to assure great strength.

The thoraco-lumbar region, or, as classed in this paper, the lumbo-sacral, is scarcely curved at all and except for the para-spinal muscles lacks good external support. What curve there is begins with a minimum of anterior convexity about 
Tio and remains mostly flat until about LI. Nineteen of these fractured bodies were compressed (42 per cent.) and the majority of dislocations were posterior. These figures indicate great strength and stability, both attributable to the ligaments and discs. With such strength goes a minimum amount of motion.

The lumbar or caudal curve is flat at L2 and becomes increasingly concave posteriorly with its apex at $\mathrm{L} 4 / 5$. Here the concavity deepens, being continued by the lumbo-sacral junction. At this point the concavity changes to the anterior aspect, as evidenced by the configuration of the sacrum. The predominant dislocation is posterior. Thirty-seven per cent. of the fractured bodies were compressed. This area is noted for its limited motion, the strength of the bones and of all ligaments except the discs and their attachments, and the propensity of the discs to give away under strain and tear loose from their attachments to the bones. My figures would seem to bear this out, and it can be deduced from them that the weakness of the discs is actually only relative and is evidence not so much of disc weakness as it is of ligamentous and bony strength. In this series only the truly acute, traumatic discs are included.

Subluxations. These are incomplete, usually anterior, partial dislocations of one or both of a pair of articular facets at the same level. The posterior facet moves upward and then forward to come to rest on the upper edge of the corresponding inferior facet. If the former moves further forward, the subluxation becomes a dislocation. Either is accompanied by rotation of the lower segment of the spine away from the subluxated or dislocated facets. If both pairs at the same level are involved, there is no rotation.

A dislocated pair of facets may become locked in their abnormal position in such a way that traction will not free them. This is recognised clinically by the diagnosis of Locked Facets. In this condition as well as in subluxated and dislocated facets, the spinal canal is lengthened as much or more than $\frac{5}{8}$ inch (Munro, 1965). Any delay in unlocking the facets, therefore, causes damage to the cord that would not otherwise have happened.

This diagnosis and its therapy can only be provided by a laminectomy. However, in the subluxations it can be assumed that, provided there is clinical evidence of relief of pressure on the cord as evidenced by cessation of symptoms after traction has been used for 24 hours, otherwise contra-indicated operative interference can be safely delayed for further traction. The capsular ligament is always torn. Subluxations cannot be shown by X-ray, and local associated fractures are not necessary to the diagnosis, although fractures elsewhere of the same or a distant vertebra are not rare. In two verified instances two cervical subluxations occurred simultaneously. Subluxations were accompanied by associated bone injuries in nine cases $(7 \cdot 3$ per cent.).

Facet dislocations can take place in reverse. The lower anterior facet moves upward and backward to rest on the upper edge and behind the superior facet. If unilateral, the upper segment of the spine rotates toward the dislocation. No rotation occurs with bilateral dislocations. This type of dislocation is not known to be preceded by a posterior subluxation.

Complications of Fractures and Dislocations. The most serious complication occurs with the fracture-dislocations. It is a Tension Hemi-pneumothorax and is caused by a compounding of the fracture into the chest cavity. It is associ- 
ated with a rupture of the chest wall and a tear of the pleura, frequently complicated by a punctured lung. The fractures that cause it are limited to the vertebrae from $\mathrm{C}_{7}$ through L2. It was present in 22 per cent. ( 17 of 77 ) thoracic fractures, one cervical and one lumbo-sacral fracture as well as in two gunshot wounds.

It is extremely lethal, is usually forgotten or missed as a diagnosis and can only be recognised by means of a bilateral thoracentesis, all other accepted signs of its presence having been practically always interpreted as 'pneumonia'. Having made the mistake myself and in the persons of my medical consultants, only to learn the truth at autopsy, an absolute rule was instituted in my department that all thoracic spine injuries that presented any variation from normal respiratory activity must be subjected to a bilateral thoracentesis, this being especially important whenever a diagnosis of pneumonia was either made or suspected. After this, tension hemi-pneumothoraces were all found prior to autopsy.

Stretched Spinal Cord (Munro, I965). This is a disabling but not a lethal complication of either a subluxation or a dislocation of the articular facets. As noted above, because the cord is firmly fastened inside the spinal canal and is inelastic and cannot elongate without injury when the canal is lengthened, a variable amount of intramyelogenous injury, which manifests itself as a variety of neurological symptoms, is thus produced. Inasmuch as subluxations are invisible by $\mathrm{X}$-rays and since they may reduce themselves without therapy or are reduced by traction soon after the damage has been done, no tangible evidence, $\mathrm{X}$-ray or otherwise, that a bone injury has ever been present is available. The surgeon is faced, therefore, with the necessity of explaining a set of paradoxical cord symptoms for which he can demonstrate no cause. All 3 I subluxations had cord symptoms and presumably stretched cords.

A variety of bizarre and unsubstantiated explanations have been offered, but without any conviction, and the result has been that such lesions have been largely disregarded. It is much better for the patient if the surgeon will accept the symptoms as real and treat the cord accordingly.

Excessive Overlap of Adjacent Laminae. This condition is only caused by extreme extension of the spine. It was noted five times-twice in the cervical, twice in the thoracic and once in the lumbo-sacral spine.

Complete Dislocation of a Vertebral Body. If this is posterior it moves completely across the spinal canal and transects the cord in its course. There were three examples (two lumbo-sacral and one caudal). Other complete dislocations were eight in number, being anterior (one caudal), anterior and lateral (one cervical and five thoracic) and rotary (one cervical).

Acute Ruptured Discs. Flexion of the spine compresses the anterior and expands the posterior edges of the discs. The posterior common spinal ligament is stretched and, with sufficient force, torn. The freed disc is pushed backward out of its place into the spinal canal, and does not return to its normal position thereafter. Such discs may be partially absorbed and are often calcified. They may also appear as hypertrophied, calcified, posteriorly-located ridges on previously damaged vertebral bodies and are not necessarily traceable to an earlier spondylosis.

Extension of the spine may also affect the disc by a mechanism that is the reverse of the above. If the disc has been forcibly pushed anteriorly and tears or ruptures the anterior common spinal ligament, it thereby weakens and diminishes the stability of the spine and changes the shape of the injured arch. However, such a 
displacement into the tissues in front of the spine has never been reported in any of my autopsied cases, nor has such a finding been mentioned, to my knowledge, in the course of surgery. Information about this is much needed.

The comparative incidence of all disc displacements, whether they were a part of a more extensive injury or not, was 5.6 per cent. in the cervical, 7.7 per cent. in the thoracic, 5 per cent. in the lumbo-sacral and 23 per cent. in the caudal areas. The comparatively greater strength of the bones and the other ligaments as compared to the weakness of the disc attachments at other spinal levels and as noted above as characterising the caudal area, appears to be supported by these findings. All I7 uncomplicated, misplaced, caudal discs in this series were acute midline extrusions causing symptoms of cauda equinal compression.

Deformed Scars. All were either associated with old fractures or were post-operative. They were formed of organised blood mixed with macerated cord tissue, bone fragments and, sometimes, calcium. The diagnosis is made from the history and from the presence of an operative scar in the midline of the back. All were associated with a cerebrospinal fluid block.

Para-spinal Muscular Paralysis. I have never seen flaccid paralysis of the para-spinal muscles associated with a traumatic injury to the spine. It has, however, been described and its aftermaths demonstrated by Perry and Nickel (I959), but their cases were the result of poliomyelitis. White (1959) mentions such paralysis in connection with trauma but gives no details. There is justifiable doubt about the validity of this observation when the nature of the muscles' nerve supplies and their co-ordinated normal motions are considered.

These muscles are controlled by both reflex and voluntary impulses which reach them through segmental distributions from the posterior branches of the various mixed spinal nerves from $\mathrm{C}_{4}$ through $\mathrm{S}_{5}$. Clinically there is abundant evidence that a considerable overlap must exist within the muscle bodies. Also, it can be predicted that the overlap will at least spread throughout any of the cord divisions, as well as across the junctions of each. The variety and extent of the co-ordinate control that is evident could not be conceived otherwise.

When a vertebra is injured or dislocated and the cord is partially or wholly transected, pain is caused. It is perceived as pain above but not at or below the transection. Even so, it is present at both areas, but at the transected area and lower, as a sensory impulse which, together with pain perceived at the higher level, activates the local protective muscle spasm in the para-spinal musculature. Further motion of the damaged parts is thus prevented, resulting in a cessation of the perceived pain but without any cessation of the still active lower and still effective stimuli. The higher stimuli are partly voluntary and partly reflex and the lower entirely reflex below the level of the transection. The spasm lasts until a substitute protective mechanism is provided.

Surgical shock may abolish the voluntary spasm for a time if the former is severe, but the reflex spasm remains, accompanied later by the return of the voluntary spasm, until both are relaxed by continuous traction. About two weeks later in the transections, the spasm below the cord injury is replaced by mass reflex spasm. This latter spasm, however, arises from an entirely different mechanism as described by McCouch et al. (1958). It is made worse by traction or hyperextension, leads to the formation of bed sores if attempts are made to control it by 
splints, and is complicated by areflexia of the bladder and bowel with overflow micturition from an atonic bladder, paralytic ileus, constipation and spasm of the voluntary external urethral and rectal sphincters (Munro, I964).

Therapy. Every spine injury (table II) has characteristics which influence its therapy. For example, as noted above, a fracture or a dislocation alters the shape of the curve in which it is located. Such a change must be taken into therapeutic account. \&ny treatment, moreover, is governed by the practical success it has in reduction, relocation and the subsequent future maintenance of the various units in their post-injury positions.

In general, two methods are used to accomplish these ends. One is Traction, supplemented by bed rest and followed six or eight weeks later by external splinting and muscle-strengthening exercises.

The second is Fusion, which depends on the early operative installation of metal plates, screws and wire loops, bone inserts, chips and slabs and which is succeeded by a short period of rest followed by early mobilisation associated with external splinting and muscle-strengthening exercises.

Fusion has no function except maintenance. Hence, any attempt to fuse in the absence of a concomitant shift of a displaced bone to an as nearly-as-possible original position, will be ineffective and may not even provide maintenance. For this reason the damaged bone must first be loosened and then moved and, only then, fixed in its new position. In the majority this requires a leverage that is impossible to apply. Use of the postero-lateral wall of the spinal canal as a substitute for this direct leverage applied to the body, will fail, despite the use of either wire or fusion, to move the latter. This is particularly true if the injury has disconnected a part or all of the former region from the latter. In the absence of such movement and adjustment, fusion, at best permanently perpetuates the malformation it has been designed to cure.

Replacement of a disc in these traumatic cases, whether it has been injured or not, by a block of grafted bone via an anterior approach with its necessary disruption of the anterior common spinal ligament and the disc attachments, in order to produce an interbody fusion, is possible but is neither feasible nor practical, although it has been used in the cervical injuries. It is also unjustifiably destructive when compared with the normal post-traumatic healing processes and does not obviate the need for previous replacement of the injured bones. This kind of surgery must be classed as meddlesome in the type of case described herewith.

The use of plaster casts or minervas for splinting forces the surgeon to accept for his patient the extra risk of death from respiratory paralysis in the cervical injuries, and the virtual certainty of bed sores as an accompaniment of the lower spinal injuries. This risk is not justified by any decrease in trouble that the patients' attendants may have been spared. Casts should never be used in these cases.

If a laminectomy-for-cause is done, at least three pairs of laminae and articular facets should be removed. If it is used as a means of diagnosis or as treatment of an injured cord, it should be extended in either direction until normal dura and cord are exposed. The addition of fusion adds shock and complicates the healing of the wound.

Regardless of the reason, however, no laminectomy, whether with or without added fusion, should be attempted during the first Io days after injury, and never at any time until after a careful assessment of any gain to be made by immediate 
surgery has been compared with any loss that might ensue by delaying the procedure. This requirement is emphasised by the mortality during this period whether before or after surgery. Eighty-four patients died at this time-an overall mortality of I4 per cent.- chiefly during the first week or within Io days of their injury. The greatest number of deaths were in the cervical group-68 out of I98, or 34.3 per cent., followed by the thoracic-I 4 out of 77 , or I $8 \cdot$ I per cent.-and then by the lumbo-sacral with two out of 82 or $2 \cdot 3$ per cent. No such deaths occurred in the caudal cases. All deaths were attributable to the associated cord injury.

Traction therapy, on the other hand, makes it possible to move injured, displaced bones from their new toward their old positions. Only the early elimination of the protective para-spinal muscular spasm and the lack of healing of any torn ligaments, however, permits them to do so. Early traction in the line of the injured part of the particular arch and, at the same time, in the direction of the long axis of the muscles, facilitates the return of the displaced bones to a normal position.

Maintenance there is then assured as soon as the ligaments heal, and later further guaranteed by the bridging with new bone or scar that often develops between the injured vertebra and its fellows above and below it. There were 23 of these latter cases-seven cervical, five thoracic, four lumbo-sacral and seven caudal. Fourteen of them had body fractures that were either compressed or wedged or both. Among them were four fracture-dislocations, two uncompressed, uncomplicated body fractures, two with a kyphosis and one with osteomyelitis of the callus.

The length of time that traction is required depends on the individual case, but averages between six and eight weeks.

My opinion, formed during 30 or more years of experience with such cases, has convinced me that traction is the more effective therapy, especially if the fracture or dislocation is complicated by a cord injury.

In General, and regardless of which therapeutic method the surgeon elects to use, any treatment should not be expected to do more than provide traction in the cervical and hyperextension in the lower injuries until surgical shock has been corrected, a satisfactory and stable respiratory exchange has been established, all complicating hemi-pneumothoraces have been cared for and all hematoraches have been drained.

Uncomplicated Fractures, without Displacement, of a Vertebral Body. No treatment other than traction therapy is either needed or indicated. If the postero-lateral canal wall is fractured or if a disc has been extruded or protruded, a laminectomy should be added, the disc removed and any fractures of the canal wall be cared for as detailed below.

Fractures of the Postero-lateral Canal Wall (Articular Facets, Laminae, Pedicles, Spinous and Transverse Processes). The basic therapy is traction, supplemented by laminectomy for diagnosis, for the removal of bone splinters, and for the amputation of subluxated, dislocated or locked facets after 24 hours of ineffective traction, as soon as the patients' condition permits thereafter.

Fracture-Dislocations. Preferred therapy for these injuries is the same as that given above for the uncomplicated fractures. It includes the performance of a laminectomy for the same indications.

Dislocations. The preferred therapy is the traction method. Although the temptation is great, the addition of internal splinting is not helpful, causes many 
complications, is ineffective, may change the shape of the involved curve and, in addition, will thus weaken the weight-bearing capacity of the fused spine.

Manual open and closed reductions are dangerous, unreliable, ineffective and contra-indicated. If metallic support is considered necessary as an aid to the maintenance of the reduction, it is better, surer and easier to amputate the locked bones rather than bother with plates, screws or wires, and thus settle the problem once for all.

Displaced Discs. Treatment is the removal of the disc through a laminectomy, and should follow the making of the diagnosis as soon as possible. To this is added any necessary inspection of the cord or cauda.

The addition of a fusion is not necessary, in my opinion, even though competent medical authority can be cited to the contrary. However, if fusion is to be done at all, it should be done late (more than one year post-injury) and then only for specific, demonstrable, physical necessities that cannot be met otherwise. Any such fusion that does not include at least five and better six contiguous laminae and spinous processes on both sides of the midline may prove inadequate and ineffective (Munro, 1956).

Injuries of the Atlas, Axis and Third Cervical Vertebra. A fractured odontoid process does not constitute an emergency but does require immediate immobilisation by traction. If the fragment is not reunited to the axis by either bone or fibrous tissue after a suitable interval, and cannot be properly controlled by splinting the neck, then fusion may have to be resorted to. It is neither necessary nor possible to fuse the occiput to more than three laminas or spines below it, and even at times this cannot be done. In any event, these grafts are notorious for their tendency to fail to unite as well as for necrosis or absorption.

This series includes 34 cases of fracture, fracture-dislocation and dislocation of the atlas, axis and third cervical vertebra. If the fourth is added to them the total is 54. The solution of the problem of the odontoid fragment that will not unite has not been surely provided as yet.

Deforming Scars. Underneath such scars lie what remains of the cord and meninges. Effective therapy requires the removal of the mass of scar from behind, from the sides and from in front of the cord and roots, if relief of pressure and any return of function is to be expected.

The scar must be removed through a new skin incision extending at least two inches above and below the original one. Working at either end and toward the centre, the dissection is deepened until the dura is reached. This and the arachnoid are pricked and the cerebrospinal fluid allowed to empty. Again working from either end but now with the dura as a guide, the mixed scar and bone is gradually freed and removed en masse. The freed dura is split lengthwise and the cord and roots exposed and cleaned. The dura should be left open with any arachnoidal leaks plugged with gel-foam, and the rest of the wound closed in layers without drains. Neither fascia, dura nor muscle should be used for transplants or hemostatics because their presence will form a second deforming scar.

Para-spinal Muscular Spasm. The only effective therapy for this condition is cervical traction with Crutchfield-type tongs or hyperextension of the spine at the lower levels. The hyperextension is produced by placing a rolled blanket between bed-springs which have been covered by bed-boards and a sponge-rubber mattress opposite any kyphos. However, the blanket roll must not be so large as to produce a degree of hyperextension that will cause occlusion of the leg veins (Munro, I943). 
First-Aid Therapy. This may prove to be lifesaving and will certainly prevent much future morbidity if it is used promptly, in accordance with the conditions, and with imagination on the part of the person who renders it. Effective substitutes for formal splints are always available. For example, in a patient with a broken neck, a folded newspaper, a folded turkish or other towel, folded underwear or other clothing, are as effective for the time being as the most expensive splint. They can be held in place by tying a piece of string around them and should be applied before moving the victim. Injuries of the lower spine need no splinting other than that of being transported on a solid structure that is wider and longer than the patient. This kind of stretcher is also necessary if the cervical cases are to be moved after splinting.

The victim should never be lifted otherwise, but if he has to be moved, must be rolled. Because, in these days, many have ingested a considerable amount of alcohol which may cause them to vomit after an injury, experience has shown that the incidence of otherwise frequent post-injury inhalation asphyxia is prevented if they are placed on their sides with their heads turned to one side, kept lower than the pelvis and supported on a hard pillow or its equivalent. The head and spine are then stabilised in that position by placing rocks or other matter wrapped in overcoats or blankets, against their front and back so that a free opportunity is provided for the mouth and throat to empty any vomitus or other secretions by gravity and without putting an unworkable strain on an already compromised respiratory system. This is contrary to the directions that have been published by the American Red Cross, but extensive experience has proved its value.

Another common complication is a full bladder. It requires prompt therapy after the patient comes under the direct care of a doctor. This consists of slow intermittent drainage of the viscus. Avoidance of rapid, complete, one-stage emptying is important if sudden death from vascular hypotension is to be avoided. Experience in the emergency rooms of a large municipal hospital has demonstrated that practically all acutely injured individuals have a full bladder on admission.

Results. There were 534 records in which the therapeutic method used could be identified.

Fusion Therapy. This had been used on 28 cases prior to admission to my department. All but one had been grafted or splinted internally elsewhere, and all but three of those that had been wired had been treated by someone other than one of my associates. The 28 had been referred to me because of disabling symptoms that had developed after fusion or metallic internal splinting. Fourteen bone grafts, six wirings, two sets of steel screws and one metal plate were removed in my department, their removal being followed by relief of the symptomatology. Of the bone grafts, eight were united, one was fractured, one was degenerated, two had developed osteomyelitis and one osteoma. Three patients had had multiple bone fusions and one multiple wirings. One case was grafted, wired, plated and fastened with metal screws.

All the other cases were treated by the Traction Method. Attention is called to the fact that with this method five original dislocations redislocated under treatment after mobilisation following reduction, only to return to their previous proper positions after further traction and immobilisation. I know of no patient that has required later fusion at any time or of any type, or whose spine has collapsed or has required further external splinting except as an aid to ambulation, after permission 
had been given to discard the earlier splints and after maximum efficiency had been attained. This includes men, women and children.

In three cases a vertebral body-fracture failed to unite under this therapy, as documented by X-ray after discharge. One was a fifth cervical with a vertical fracture that was also comminuted and had dislocated anteriorly. Another had an un-united fracture of the laminae and an anterior dislocation of the fifth lumbar vertebra. The third had a compression fracture of the bodies of the second, third and fourth lumbar vertebrae. No permanent disability developed after their discharges.

A complication that might possibly be traced to the bone injury and its therapy, was a necrosis of the cord in five cervical cases. No cause could be certainly designated in any one of them. Two died from anoxia in 24 hours and two days respectively after their injuries, and a third from a pulmonary embolus after five days. Four had transected cords and the fifth was a partial cord injury who survived operative removal of a disc and proved at subsequent exploration to have a degenerated cord. The bones involved were the fifth and sixth and the disc 5/6.

Conclusions. It is futile and misleading to try and make a comparative estimate of the relative efficiency of fusion and traction therapies as described and reported herewith. The two series are not statistically comparable. The reader must, therefore, make up his own mind on the subject, providing he has had enough experience to justify an opinion. He can include, if he so wishes, a consideration of the analyses that form the bulk of this paper.

The evidence summarised here, which I have collected over many years, has formed the basis for my opinion, nevertheless, that fusion is only rarely justified or effective, and then only under the limitations stated above; and that traction therapy is always otherwise preferable. After all, the treatment that should be used is the one that proves best for the patient.

Any physician or surgeon who advocates fusion-type therapy for fractures and dislocations of the spine must first ask himself and then answer the following question: Is it good surgical practice to reduce a fracture before fusing or splinting it? This is a 'loaded question' which has been modelled after the question President Lincoln asked of Stephan Douglas in the famous slavery debates at the start of the Civil War.

If it is answered 'Yes', then neither fusion nor splinting of spinal fractures or dislocations until after a period of traction has been employed to make such a reduction. The corollary to this is that the only possible use for fusion is for maintenance, which in turn limits its use, if otherwise suitable to no earlier a period after the injury than one year and restricts it as therapy to specific, demonstrable, otherwise uncorrectable problems inherent in maintenance.

If the answer is 'No' the surgeon thereby goes on record as disagreeing with virtually everybody else's opinion and perpetuates a deformity. He must, therefore, hold himself responsible for any future disability despite any specious arguments or reasons to the contrary. 


\section{SUMMARY}

A review and analysis of the records of 583 patients who had been admitted to my private care at the Boston City Hospital over 30 years are analysed and classified in the light of a previous paper dealing with the part played by the spinal ligaments in the maintenance of stability and weight-bearing. Traction and Fusion-withinternal splinting therapies are analysed and my experience with a small series of the latter as well as a large series of 506 patients treated by traction therapy are presented for the reader's information. No statistical comparison is offered. Attention is particularly drawn to the importance of fractures of the posterior, lateral walls of the spinal canal, tension hemo-pneumothorax and hematorachis, and to the significance of the shape of the spinal arches in determining the frequency and site of fractures and dislocations and their effect on weight-bearing. The conclusion is reached that fusion may be useful in certain instances but no sooner than a year after the injury, and that in all other instances the preferable and indeed the only treatment that offers any hope of recovery and the avoidance of morbidity is traction therapy supplemented by the judicious use of laminectomies for diagnosis and treatment or both.

\section{RÉSUMÉ}

Une revue et analyse des dossiers des 583 malades admis dans mon service du Boston City Hospital, sur une période de 30 ans, ont été analysés et classifiés à la lumière d'un précédent article où a été décrit le rôle joué par les ligaments spinaux dans le maintien de la stabilité et de la mise en charge.

Le traitement par traction et fusion par immobilisation interne est analysés et mon expérience avec une petite série de malades traités par cette dernière méthode contre celle, assez large de 506 malades traités par traction est présentée au lecteur. Aucune comparaison statistique n'est offerte.

L'attention est particulièrement attirée sur l'importance des fractures des parois postérieures et latérales du canal spinal, l'hémo-pneumothorax, l'hématorachis, de la forme de l'arc spinal quant à la fréquence et le siège des fractures et dislocations et de leurs effetssur la mise en charge.

Nous sommes arrivés è la conclusion que la fusion peut être utile dans certaines circonstances mais seulement avec un recul d'au moins un an, après l'accident. Dans les autres cas, par contre, le seul traitement préférable qui puisse offrir un espoir de récupération en évitant la mortalité, est la thérapeutique par traction, à laquelle s'ajoute le choix judicieux d'une laminectomie en vue d'établir le diagnostic et le traitement.

\section{ZUSAMMENFASSUNG}

Im Anschluss an eine frühere Arbeit über den Anteil, den die Bänder der Wirbelsäule an der Erhaltung der Stabilität und Belastbarkeit nehmen, werden die Krankenblätter von 583 Patienten analysiert, die ich in den letzten 30 Jahren privat am Boston City Hospital behandelt habe.

Schädelzug und operative Behandlung (Knochenspan-und andere Fixierung) werden einer Analyse unterworfen. Meine Erfahrung mit einer kleinen Zahl von operativen und einer grossen Gruppe von konservativ behandelten Fällen (Schädelzug) wird beschrieben. Eine statistische Auswertung wird nicht geboten.

Besondere Aufmerksamkeit wird gewidmet: den Frakturen der Seiten und Hinterwände des Spinalkanals, den Fällen von Spannungshaemopneumothorax und der Haematomyelie; und der Bedeutung der Anatomie der Wirbelbögen für die relative Häufigkeit und Lokalisation von Frakturen und Luxationen und deren Einfluss auf die Belastbarkeit. 
Die Meinung wird vertreten, dass operative Fixierung in einigen Fällen von Nutzen sein kann, aber nicht früher als ein Jahr nach dem Unfall. Inallen anderen Fällen stellt Schädelzug die Methode der Wahl dar als die einzige Methode, die irgendwelche Hoffnung auf neurologische Erholung and auf Vermeidung von Komplikationen bietet. Hinzu kommt nach sorgfältiger Auswahl in einigen Fällen die Laminektomie für diagnostische und therapeutische Zwecke.

\section{REFERENCES}

BRAIN, W. R. (I954). Lancet, I, 687.

Crutchfield, W. G. (1954). F. Amer. med. Ass. 155, 29.

McCouch, G. P., Austin, George M., LiU, C. N. \& LiU, C. Y. (1958). F. Neurophysiol. 2I, 205.

Munro, Donald (1943). F. Amer. med. Ass. 122, 1055.

Munro, Donald (1956). New Engl. F. Med. 254, 243.

Munro, Donald (1960). New Engl. F. Med. 262, 839.

Munro, Donald (196i). New Engl. F. Med. 264, 573.

Munro, Donald (I964). New Engl. F. Med. 270, i I67.

Munro, Donald (1965). Submitted for Publication to Paraplegia.

Perry, J. \& Nickel, V. L. (I959). F. Bone ft. Surg. 4IA, 37.

White, J. C. (I959). F. Bone ft. Surg. 4IA, I I. 